\title{
Arbusküler Mikorizal Fungus Aşılamasının Doğu Kayını (Fagus orientalis Lipsky.) Fidanlarının Büyüme Performansı ve Adaptasyon Başarısı Üzerine Etkilerinin Araştırılması
}

\author{
Halil Barış ÖZEL ${ }^{1}$, Şahin PALTA ${ }^{1 *}$, Erkan ÇAKMAKLI ${ }^{2}$ \\ ${ }^{1}$ Bartın Üniversitesi, Orman Fakültesi, Orman Mühendisliği Bölümü, Bartın \\ ${ }^{2}$ Bartın Üniversitesi, Lisansüstü Eğitim Enstitüsü, Orman Mühendisliği Anabilim Dalı, Bartın
}

\section{Öz}

$\mathrm{Bu}$ çalışmada, doğu kayını (Fagus orientalis Lipsky.) fidanlarına arbusküler mikorizal fungus (AMF) aşılaması yapılmıştır. AMF aşılı ve aşısız tüplü fidanlar Yenice yöresinde 3 farklı yükselti kademesine (200-400 m, 400-600 m ve 600-800 m) dikilmiş ve arazi performansları izlenmiştir. Hem yükselti kademelerinin kendi içinde hem de kendi arasında karşılaştırmalar yapılmış ve fidanlıkta kantitatif karakterler (yükselti, boy, kök boğaz çapı, fidan taze ağırlığı, fidan kuru ağırlığı, kök uzunluğu, yan kök sayısı ve yaşama yüzdesi) ölçülmüştür. Ölçümlerin sonucunda mikorizalı ve kontrol fidanları arasındaki karşılaştırmalar varyans analizi ve Duncan testi yardımıyla analiz edilmiş ve en az \%95 güven düzeyinde anlamlı olan karakterler kendi arasında oluşturduğu homojen gruplar ile birlikte verilmiştir. Araşırımada AMF uygulaması sonrasında kontrol fidanları ile yapılan karşılaştırmalar sonucunda denemenin tamamında ortalama boy büyümesinin $30,01-43,56 \mathrm{~cm}$, kök boğaz çapının $0,52-0,85 \mathrm{~mm}$, fidan taze ağırlığının 7,97-9,07 g, fidan kuru ağırlığının 4,45-6,52 g, kök uzunluğunun 22,77-31,39 cm, yan kök sayısının 6,10-14,80 adet ve yaşama yüzdesinin \%62,54-95,12 arasında değiştiği tespit edilmiştir. Tüm yükselti kademelerinde incelenen tüm morfolojik karakterlerde ve yaşama yüzdesinde AMF'li fidanlar kontrol fidanlarına üstünlük sağlamıştır. Özellikle yaşama yüzdesi değişkeninde AMF uygulanan kayın fidanlarının kontrol fidanlarına göre \%30’a yakın bir üstünlük gösterdiği belirlenmiştir.

Anahtar Kelimeler: Doğu kayını, Arbusküler mikorizal funguslar, Büyüme, Adaptasyon yeteneği.

\section{Investigation of the Effects of Arbuscular Mycorrhizal Fungi Inoculation on Growth Performance and Adaptation Success of Oriental Beech (Fagus orientalis Lipsky.) Seedlings}

\begin{abstract}
In this study, arbuscular mycorrhizal fungi (AMF) inoculation was performed in the oriental beech (Fagus orientalis Lipsky.) seedlings. The tubular seedlings inoculated AMF and non-AMF were planted in 3 different elevation zones (200-400 m, 400-600 $\mathrm{m}$ and 600-800 m) in Yenice region and their field performances were monitored. Comparisons were made both within and between the elevation stages and quantitative characters (elevation, height, root collar diameter, seedlings fresh weight, seedlings dry weight, root length, number of side roots and percent of survival) were measured in the nursery. As a result of the measurements, comparisons between AMF and control seedlings were made with the help of variance analysis and Duncan test, and characters that are significant at least 95\% confidence level are given together with homogeneous groups formed among themselves. As a result of comparisons made with control seedlings after AMF inoculation in the study, the mean height growth in the whole sample plots were found as $30.01-43.56 \mathrm{~cm}$, root collar diameter $0.52-0.85 \mathrm{~mm}$, seedlings fresh weight 7.97-9.07 g. It was determined that seedlings dry weight was 4.45-6.52 g, root length 22.77-31.39 cm, the number of side roots ranged between 6.10-14.80 pieces and the percentage of survival 62.54-95.12\%. In all morphological characters and percentages of survival studied at all elevation levels, the seedlings with AMF provided superiority to the control seedlings. Especially in the percentage of survival variable, it was determined that oriental beech seedlings, where AMF was applied, had a superiority of nearly $30 \%$ compared to control seedlings.
\end{abstract}

Keywords: Oriental beech, Arbuscular mycorrhizal fungi, Growth, Adaptation ability. 


\section{Giriş}

Ülkemizde çok farklı yerel koşullar nedeniyle fizyolojik özellikleri birbirinden farklı çeşitli bitkiler ortaya çıkmıştır. Farklı ekolojik koşulların etkisiyle tür bileşimi ve meşcere kuruluşları açısından ülkemiz oldukça zengin orman alanlarına sahiptir. Ancak bu orman alanlarının önemli bir kısmı çeşitli faktörlerin etkisiyle verim güçlerini büyük düzeyde kaybetmiş ve yeniden sslah edilmeyi beklemektedir (OGM, 2006). Bu nedenle, ormanların devamlılığının sağlanarak gelecek kuşaklara sağlıklı ve kaliteli bir şekilde aktarılması ve bu önemli doğal kaynağın içinde bulunan ekosistemin tüm ögeleri ile birlikte sürdürülebilir yönetimi gerçekleştirilmelidir (Özel, 2007).

Ülkemizde 2 milyon hektara yakın alana sahip olan Doğu kayını (Fagus orientalis Lipsky.) ormanları, türün odununun değerli olması ve orman ekosistemindeki fonksiyonel özelliklerinin üstünlüğü nedeniyle birçok bölgede yapılan planlı ve plansız kesimler nedeniyle önemli tahriplere uğramıştır. Bu durum özellikle orman için sağladığı besin maddesi kaynağı özelliği ile önemli bir ekosistem öğesi olan doğu kayını türünü önemli bir konuma getirmekle birlikte türün gençlikte yavaş büyümesi ve açık alan koşullarından zarar görmesi ve erken yaşlardan itibaren sahip olduğu yüksek tepe elastikiyeti nedeniyle kolayca morfolojik özelliklerinde meydana gelen deformasyonlara bağlı olarak sürdürülebilir yönetim ve ormanların devamlılığının sağlanmasını güçleştirmektedir. Bu nedenle doğu kayını gibi özellikle ilerleyen yaşlarda azmanlaşan ve ardaklanma özelliği olan duygulu bir türün ormanlarının doğal ya da yapay yöntemlerle devamlılığının sağlanmasında başarılı olabilmek için öncelikle yetişme ortamı etüdlerinin çok sağlıklı ve detaylı gerçekleştirilmesi gerekmektedir (Saatçioğlu, 1969; Atay, 1987; Atalay, 1992).

Bozuk olan doğu kayını ormanlarının yeniden verimli hale getirilmesi, bu orman gen kaynaklarının devamlılığının sağlanması açısından oldukça önemlidir. Ancak, genellikle dikim yoluyla gerçekleştirilen kayın rehabilitasyon ve yapay gençleştirme çalışmalarında fidan kalitesinin düşüklügüune, yetiştirme tekniğine ve arazideki dikim ortamlarının verim gücünün düşüklüğüne bağlı olarak yaşanan dikim şokları türün adaptasyon yeteneğini düşürmektedir. Bozuk kayın ormanlarının ıslahı amacıyla yapılacak olan bu tür çalışmalarda fidan kalitesini iyileştirmek ve özellikle dikim sonrası yaşanan dikim şokunu atlatabilmek amacıyla kök hacmi yüksek ve topraktaki su ve besin maddelerinden yeterince yararlanabilen fidanlar yetiştirmek gerekmektedir. Bu kapsamda dünyada modern ve entansif ormancılık uygulamaları içinde yer alan fakat ülkemizde yeterli araştırma yapılmamış ve ormancılık pratiğine yeterince aktarılamamış olan Arbusküler Mikorizal Fungus (AMF) aşılamaları gittikçe önem kazanmaktadır. Bu nedenle, ülkemizin önemli asli orman ağacı türlerinden biri olan doğu kayınına (Fagus orientalis Lipsky.) ait bozuk vasıflı ormanların dikim yoluyla iyileştirilme çalışmaları kapsamında, dikim materyali olarak kullanılacak fidanlara AMF aşılaması yapılarak dikim başarısı ve adaptasyon yeteneğini yüksek seviyelere çekmek için bu çalışma yapılmıştır. Çünkü AMF bitkinin rizosfer bölgesindeki tüketim zonunu genişleterek toprakta bulunan su ve bitki besin elementlerinden daha fazla faydalanmasını sağlamaktadır. Ayrıca, AMF toprak kaynaklı kök patojenlerine karşı bitkinin direncini artırmaktadır.

$\mathrm{Bu}$ çalışma ile doğu kayını fidanlarına AMF aşılamasının, fidanların büyüme performansı ve adaptasyon yeteneğini nasıl etkileyeceği sorusunun cevabı araştırılmıştır. Bu araştırmanın amacı, tarafımızdan AMF aşılaması yapılan kayın fidanlarının üç farklı yükselti kademesine dikilmesi ile fidanların gelişimi ve tutma başarısı üzerindeki etkilerini araştırmaktır. Bu kapsamda AMF aşılamasının etkilerini görebilmek için aşılama yapılmış ve yapılmamış kayın fidanları her üç yükselti kademesine de dikilmiştir. AMF aşılanmamış olan kontrol fidanları ile AMF aşılanmış fidanların boy, kök boğazı çapı, yaprak eni-boyu, fidan taze-kuru ağırlığı, gövde ve kök taze-kuru ağırlığı, kök sayısı, kök uzunluğu, katlılık oranı gibi kantitatif parametreler ölçülerek hesaplanmış ve farklılıklar tespit edilmiştir. Ayrıca aşılama yapılan ve yapılmayan fidanların yaşama yüzdeleri belirlenmiş, her üç yükselti kademesindeki adaptasyon yetenekleri saptanmıştır.

\section{Materyal ve Metot}

\subsection{Materyal}

Araştırmada Tefen orijinli, 1+1 yaşlı ve tüplü doğu kayını fidanlarına endo arbusküler mikoriza aşılaması yapılmıştır Aşılama işleminde Glomus cinsine ait funguslar kullanılmıştır. Gökçebey Orman Fidanlık Müdürlüğü’nde gerçekleştirilen bu uygulamada toplam 480 adet doğu kayını fidanı kullanılmıştır (Şekil 1). 


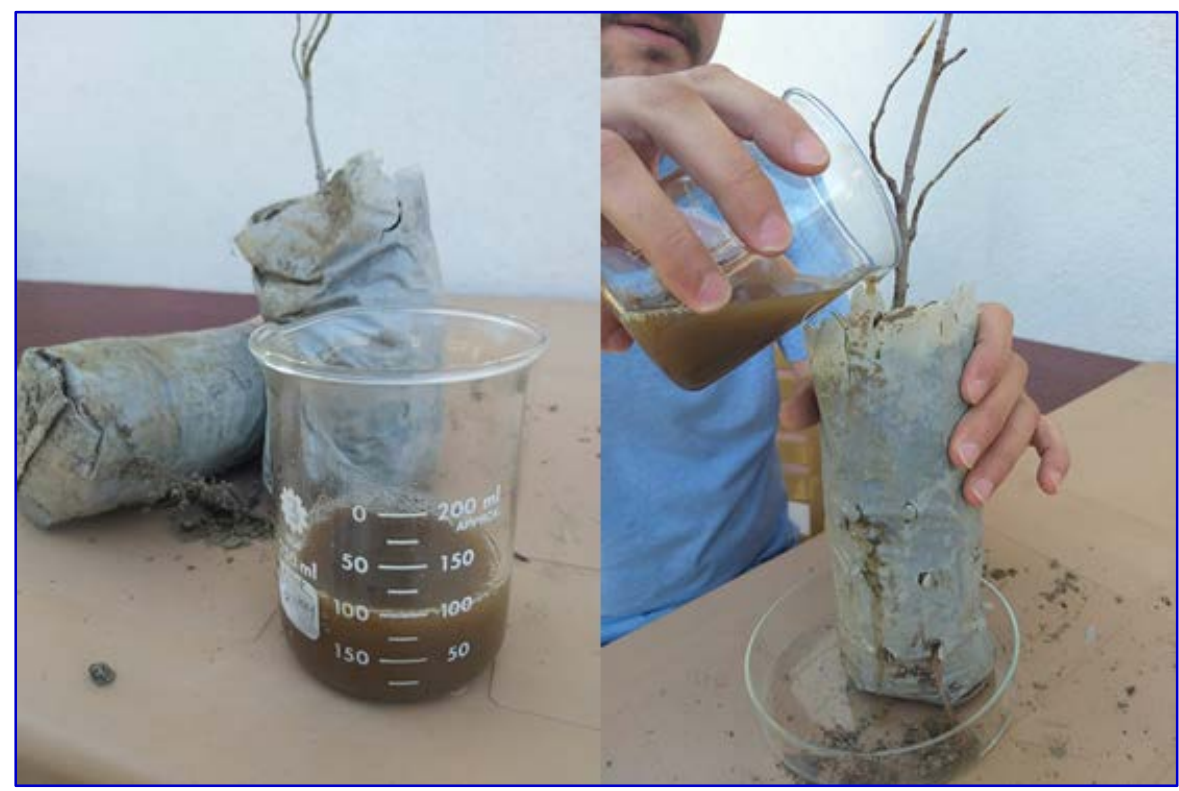

Şekil 1. Tefen orijinli, 1+1 yaşlı ve tüplü doğu kayını fidanlarına arbusküler mikorizal fungus aşılaması.

AMF uygulanan doğu kayını fidanlarının belirtilen 3 farklı yükselti kademesinde (200-400 m, 400-600 m. ve 600800 m.) AMF uygulanmayan fidanlar ile karşılaştırmalı olarak gerçekleştirilen arazi denemeleri Yenice yöresinde yapılmıştır (Şekil 2). Arazi uygulamalarının gerçekleştirildiği Yenice yöresinde her 3 yükselti kademesinde bakı kuzeybatı olup, alan Avrupa-Sibirya Fitocoğrafik bölgesinin Öksin kuşağı sınırları içinde kalmaktadır. Alanlarda toprak derin olup, kumlu-killi-balçık tekstüründe ve granular strüktürdedir. Hakim rüzgar batıdan esmekte olup vejetasyon süresi 6 aydır. Araştırma alanında ortalama sıcaklık 18,2- 21,4 ${ }^{\circ} \mathrm{C}$ ve ortalama yıllık yağış $1032-1146$ mm’dir (Anon., 2019).

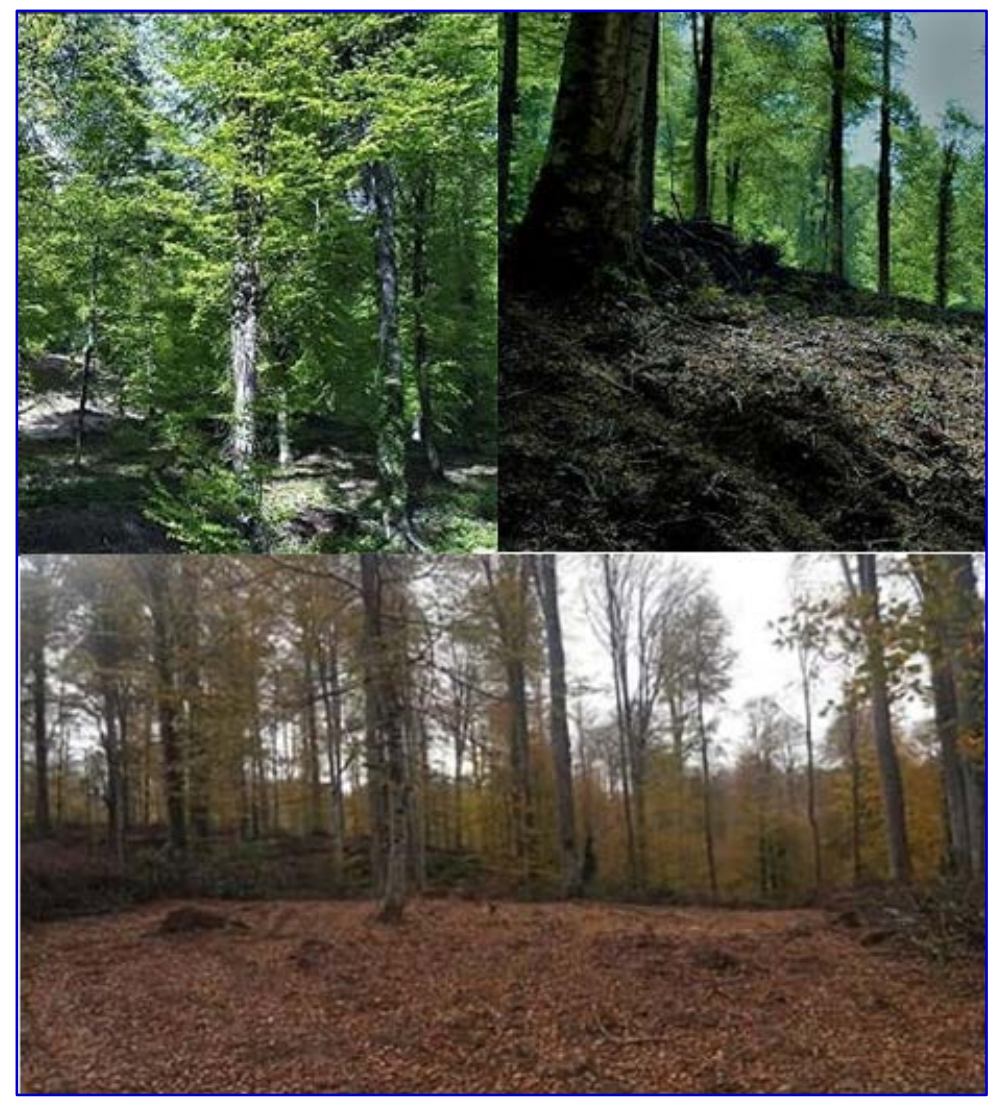

Şekil 2. Üç farklı yükselti kademesinde uygulama yapılan deneme alanları. 


\subsection{Metot}

\subsubsection{Arbusküler Mikorizal Fungus Aşılaması ve Doğu Kayını Fidanlarının Araziye Dikimi}

AMF aşılamasında ERS (Endo Root Soluble) marka yurt dışı kaynaklı, Glomus intraradices, Glomus aggregatum, Glomus mosseae, Glomus clarum, Glomus monosporus, Glomus deserticola, Glomus brasilianum, Glomus etunicatum, Gigaspora margarita türlerinden oluşan karışım kullanılmıştır. AMF aşılaması her tüplü fidan için 25 adet spor olacak şekilde gerçekleştirilmiştir. Aşı kaynağı sulama suyuna karıştırılarak tüplü fidanlara uygulanmıştır. AMF aşılaması yapılan fidanlar fungusun kolonize olabilmesi için 2 ay süre ile bekletilmiştir. AMF aşılaması yapılan ve yapılmayan tüplü fidanlar Karabük ili Yenice yöresinde üç farklı yükselti kademesine (200-400 / 400-600 / 600-800 metre) her bir tekrarda 40 adet olacak şekilde üç tekrarlı olarak rastlantı parselleri deneme desenine göre toplam 120 aşılı ve kontrol olarak da 40 aşısız fidan olacak şekilde dikilmiştir (Tablo 1). Böylece her bir kademede 160 adet fidan olacak şekilde, üç kademede toplam 480 adet fidan dikimi yapılmıştır.

Tablo 1. Deneme deseni.

\begin{tabular}{llllll}
\hline Yükselti Kademesi (m) & $\begin{array}{l}\text { 1. Tekrar } \\
\text { AMF (+) } \\
\text { (adet fidan) }\end{array}$ & $\begin{array}{l}\text { 2. Tekrar } \\
\text { AMF (+) } \\
\text { (adet fidan) }\end{array}$ & $\begin{array}{l}\text { 3. Tekrar } \\
\text { AMF (+) } \\
\text { (adet fidan) }\end{array}$ & $\begin{array}{l}\text { Kontrol } \\
\text { AMF (-) } \\
\text { (adet fidan) }\end{array}$ & $\begin{array}{l}\text { Toplam } \\
\text { (adet fidan) }\end{array}$ \\
\hline 1. Kademe (200-400) & 40 & 40 & 40 & 40 & 160 \\
2. Kademe (400-600) & 40 & 40 & 40 & 40 & 160 \\
3. Kademe (600-800) & 40 & 40 & 40 & 40 & 160 \\
$\begin{array}{l}\text { Toplam Fidan Sayısı } \\
\text { (adet) }\end{array}$ & 120 & 120 & 120 & 120 & 480 \\
\hline
\end{tabular}

Dikilen fidanların arazi performansları (büyüme ve adaptasyon başarıları) izlenmiştir. Dikimden önce ve dikimden sekiz ay sonra AMF aşılanmamış olan kontrol fidanları ile AMF aşı1ı fidanların boy, kök boğazı çapı, yaprak eni-boyu, fidan taze-kuru ağırlığı, gövde ve kök taze-kuru ağırlığı, kök sayısı, kök uzunluğu, katlılık oranı gibi kantitatif parametreler belirlenmiş ve kaydedilmiştir (Şekil 3).

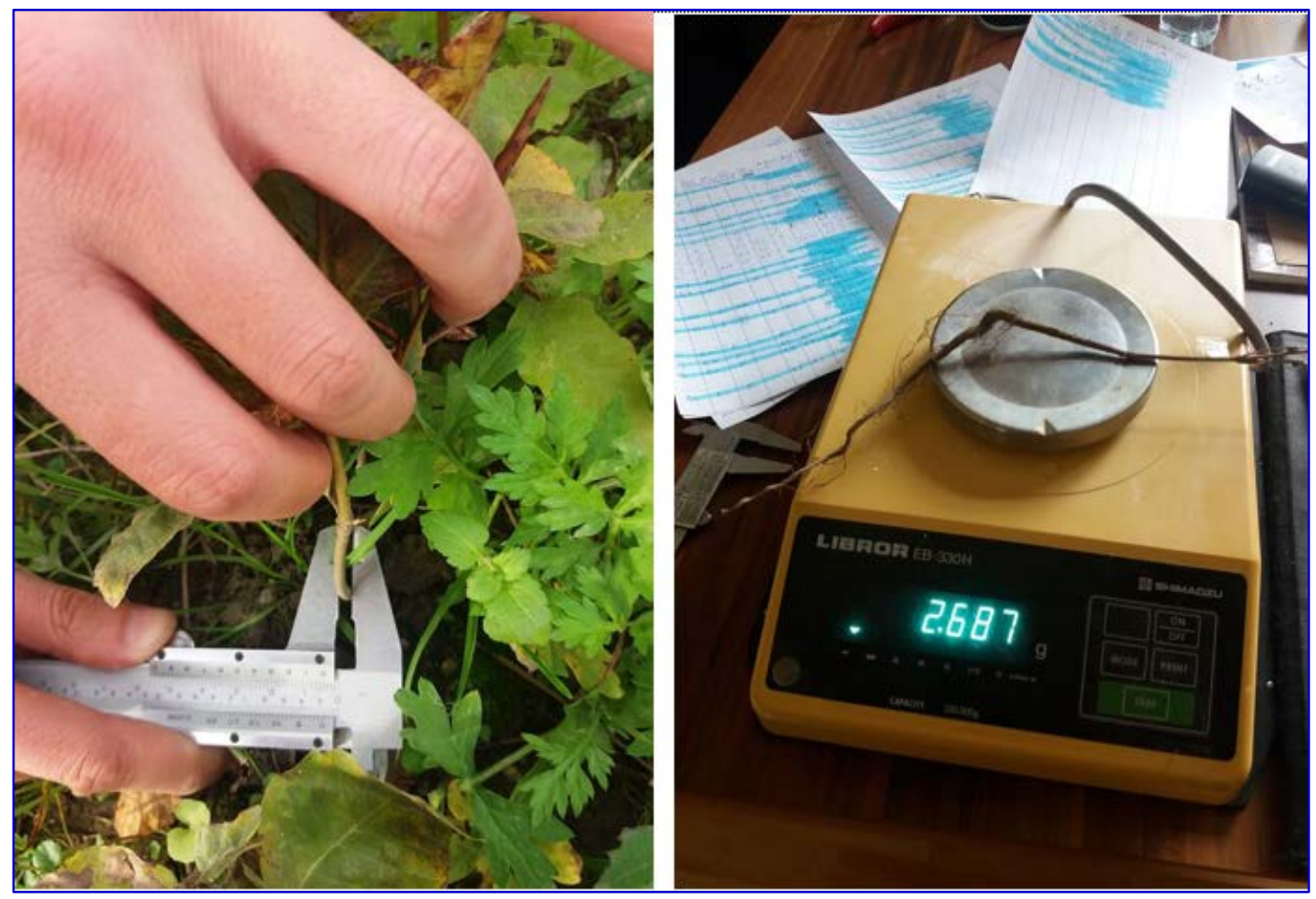

Şekil 3. Dikilen fidanların arazi performanslarının izlenmesi. 


\section{3. İstatistiki Analizler}

Arbusküler mikorizal fungus aşılamasının kayın fidanlarının büyüme performansı ve adaptasyon başarısını belirlemek amacı ile tek yönlü varyans analizi (One-way ANOVA) yapılmıştır. Varyans analizi sonucunda istatistiki açıdan anlamlı farklılık çıkması durumda gruplandırma için \%95 güven düzeyinde Duncan testi yapılmıştır.

Genel olarak bakıldığında kısaca fidanlıkta mikoriza aşılanan fidanlarda boy, kök boğaz çapı, fidan taze ağırlığ1, fidan kuru ağırlığı, kök uzunluğu, yan kök sayısı, kök uzunluğu, yaşama yüzdesi gibi kantitatif karakterlerin ölçümü yapılmıştır. Hem yükselti kademelerinin kendi içinde hem de kendi arasında karşılaştırmaları yapılmış ve fidanlıkta ölçülen kantitatif parametreler tekrar edilmiştir. Gerek fidanlık aşamasında gerekse arazi aşamasında mikorizalı ve kontrol fidanları arasındaki karşılaştırmalar varyans analizi (ANOVA) ve duncan testi yardımıyla yapılmıştır. Bu istatistiki analizlerin tamamı SPSS paket istatistik programı kullanılarak gerçekleştirilmiştir. Analizlerin tamamında en az $\mathrm{P}<0,05$ güvenlik düzeyi aranmış, en az \%95 güven düzeyinde anlamlı olan parametreler arasında oluşan homojen gruplar ile birlikte verilmiş ve tablo haline getirilmiştir (SPSS 16.0).

\section{Bulgular ve Tartışma}

\subsection{Yükseltinin Etkisine İlişkin Bulgular}

Yapılan istatistiksel analizler sonucunda AMF uygulanmış doğu kayını fidanlarına ilişkin kantitatif karakterler üzerinde \%95 güven düzeyinde yükselti kademesinin etkili olduğu ve özellikle ikinci ve üçüncü yükselti kademelerinin araştırmanın gerçekleştirildiği Yenice yöresinde kayının optimal ekolojik koşullarına daha yakın koşullara sahip olması nedeniyle daha yüksek değerler gösterdiği belirlenmiştir.

\subsection{Kantitatif Fidan Karakteristiklerine İlişkin Bulgular ve Tartışma}

Çalışmaya konu olan kantitatif karakterlerden, fidan boyunun \%99,9 güven düzeyinde anlamlı olduğu görülmektedir. Boy karakterinin ortalama değerleri Tablo 2'de verilmiştir. Ayrıca, varyans analizi sonuçlarına göre türlerin istatistiki olarak aralarında \%95 güven düzeyinde anlamlı farklılıklar bulunan karakterlerden oluşturulan homojen gruplara göre boy karakterinde en yüksek değerler AMF uygulanmış fidanlardan elde edilmiştir (Tablo 2). Buna göre araştırmada incelenen doğu kayını fidanlarının boy büyümesi değerlerinin 30,0143,56 cm arasında değiştiği ve en yüksek boy büyümesi değerinin AMF aşılı fidanlardan elde edildiği belirlenmiştir. Araştırma konusunu oluşturan orman ağaçlarına AMF uygulaması ile ilgili olarak yapılan araştırma çalışmaları henüz çok yeni olup gerek ulusal gerekse uluslararası literatürde yeterli düzeyde bulunmamaktadır. Bu kapsamda boy değişkeninde olduğu gibi diğer tüm morfolojik karakterlerde ve yaşama yüzdesinde yapılan tartışmalar daha çok tarımsal ve tarımsal ormancılık uygulamalarında kullanılan bitkilere uygulanan AMF aplikasyonlarının sonuçları ile gerçekleştirilmiştir. Buna göre Cannablas sativa'da gerçekleştirilen bir araştırmada AMF uygulamasının fidanların boy büyümesini önemli ölçüde artırdığı belirtilmiştir (Citterio vd., 2005).

Kök boğaz çapı karakterinin \%99,9 güven düzeyinde anlamlı olduğu görülmektedir. Kök boğaz çapı karakterinin ortalama değerleri Tablo 2'de verilmiştir. Varyans analizi sonuçlarına göre türlerin istatistiki olarak aralarında \%95 güven düzeyinde anlamlı farklılıklar bulunan karakterlerden oluşturulan homojen gruplara göre çap karakterinde en yüksek değerler AMF uygulanmış fidanlara aittir (Tablo 2). Kök boğaz çapı ilk yıllardan itibaren fidan gelişimini boy değişkeni ile birlikte en iyi yansıtan kantitatif parametrelerden birisi olmuştur. Bu kapsamda doğu kayını fidanlarının kök boğaz çapı gelişimlerinin 0,52-0,85 mm. arasında değiştiği ve en yüksek kök boğaz çap1 gelişiminin AMF aşılı doğu kayını fidanlarında meydana geldiği saptanmıştır. Bu konuda farklı tarım bitkilerinde gerçekleştirilen AMF uygulamalarında da henüz birinci yıl sonundan itibaren AMF uygulamasının çok ciddi artışlar meydana getirerek kök hacmini güçlendirdiği ve sahip olunan beslenme gücü seviyesini oldukça yüksek düzeylere çıkardığı tespit edilmiştir (Hodge vd., 2009).

Fidan (F) taze ağırlık karakterinin \%99 güven düzeyinde anlamlı olduğu görülmektedir. Fidan taze ağırlık karakterinin ortalama değerleri Tablo 2'de verilmiştir. Varyans analizi sonuçlarına göre türlerin istatistiki olarak aralarında \%95 güven düzeyinde anlamlı farklılıklar bulunan karakterlerden oluşturulan homojen gruplara göre çap karakterinde en yüksek değerler AMF uygulanmış fidanlarda tespit edilmiştir (Tablo 2). Fidan taze ağırlığı ilk yıllardan itibaren özellikle yaşama yüzdesinin, adaptasyon yeteneğinin ve fotosentez düzeyinin belirlenmesi yönünde önemli bir metrik karakterdir. Bu kapsamda gerçekleştirilen ölçümlerde fidan taze ağırlığının 7,97-9,07 g arasında değiştiği ortaya çıkmıştır. Buna göre AMF uygulamasının fidan taze ağırlığı üzerinde çok önemli artışlara neden olduğu ve bu durumun özellikle fotonsentez hızı ve miktarı açısından fidanlarda olumlu 
gelişmelerin meydana geldiğinin bir göstergesi olarak düşünülebilir. Bu konuda ökaliptus fidanlarında yapılan bir araştırmada da AMF uygulamasının fidan taze ağırlığını yaklaşık olarak kontrol numunelerine göre 2 katına kadar artırdığı belirlenmiştir (Janos vd., 2013).

Fidan kuru ağırlık karakterinin \%99,9 güven düzeyinde anlamlı olduğu görülmektedir. Fidan kuru ağırlık karakterinin ortalama değerleri Tablo 2'de verilmiştir. Varyans analizi sonuçlarına göre türlerin istatistiki olarak aralarında \%95 güven düzeyinde anlamlı farklılıklar bulunan karakterlerden oluşturulan homojen gruplara göre $\mathrm{F}$ kuru ağırlık karakterinde AMF uygulanmış olan fidanlar kontrol grubuna göre yüksek değerler göstermiştir (Tablo 2). Buna göre araştırmada AMF aşılanmış ve kontrol numunelerinden alınan örneklemelerde yapılan tartımlar sonucunda fidan kuru ağırlığının 4,45-6,52 g. arasında değiştiği saptanmıştır. Bu değişken açısından da AMF uygulamasının taze ağırlıkta olduğu gibi pozitif etkilerinin olduğu kontrol numuneleri ile yapılan karşılaştırmalar sonucunda ortaya çıkmıştır. Özellikle fidan kuru ağırlığının fidanların kalite sınıflarını yakından ilgilendiren ve etkileyen bir değişken olduğu düşünüldüğünde, AMF uygulamalarının doğu kayını fidanlarının kalitesini de olumlu yönde etkilediği söylenebilir. Bu konuyla ilgili olarak bazı önemli tarım bitkilerinde gerçekleştirilen araştırmada da mikoriza uygulamalarının fidan özelliklerini ve kalitelerini olumlu yönde etkilediği ve özellikle katlılık ve gürbüzlük indisi seviyelerini artırdığı tespit edilmiştir (Koch vd., 2017). Bu sonuçlar da doğu kayını fidanlarının gelişimi ve kalitesi üzerinde AMF uygulamalarının etkisinin olumlu sonuçlar ortaya çıkardığına yönelik elde edilen bulguları desteklemektedir.

Kök uzunluğu karakterinin \%99 güven düzeyinde anlamlı olduğu görülmektedir. Kök uzunluğu karakterinin ortalama değerleri Tablo 2'de verilmiştir. Varyans analizi sonuçlarına göre türlerin istatistiki olarak aralarında \%95 güven düzeyinde anlamlı farklılıklar bulunan karakterlerden oluşturulan homojen gruplara göre kök uzunluğu karakterinde AMF uygulanmış fidanlara ait değerler kontrol grubundan daha yüksek çıkmıştır (Tablo 2). Fidanlardaki kök uzunluğunun 22,77-31,39 cm. arasında değiştiği belirlenmiştir. Bu durum doğu kayını fidanlarına yetersiz su kaynaklarının bulunduğu toprak koşullarında hem daha derin hem de yatay mesafede daha geniş alanlardaki mevcut su kaynaklarına ulaşma imkânı sağlayabilecektir. Bu mısır türlerinde gerçekleştirilen araştırmalarda AMF ve diğer mikoriza uygulamalarının kök ve sürgün gelişimi üzerinde çok olumlu etkiler meydana getirerek bitkilerin değişik stres faktörlerine karşı olan dayanıklılıklarının artırılabileceği ve gelişim gerilemelerinin önüne geçilebileceği vurgulanmaktadır (Kothari vd., 1990). Bununla birlikte, Poss vd. (1985) yaptıkları çalışmada, mikorizalı bitkilerin mikorizasız bitkilere göre tuzlu koşullarda daha fazla verim artışı sağladıklarını ve yine daha fazla fosfor kapsadıklarını bildirmişlerdir. Kılavuz (2006) tarafından Van yöresinde yapılan bir çalışmada, bitkisel verimin sınırlandırıldığı tuzlu alanlarda mikoriza uygulaması (Glomus intraradices) ile bitki gelişiminin genelde olumlu etkilendiği belirtilmiştir. Demirbaş (2012) tarafından Çukurova bölgesinde yapılan araştırmada mikoriza aşılaması yapılan bitkilerin mikoriza aşılaması yapılmayan bitkilere göre veriminin ve N, P, K ve Zn elementleri alımının arttığ 1 saptanmıştır.

Yan kök sayısı karakterinin \%99 güven düzeyinde anlamlı olduğu görülmektedir. Yan kök sayısı karakterinin ortalama değerleri Tablo 2'de verilmiştir. Varyans analizi sonuçlarına göre türlerin istatistiki olarak aralarında \%95 güven düzeyinde anlamlı farklılıklar bulunan karakterlerden oluşturulan homojen gruplara göre yan kök sayısı karakterinde en yüksek değerler AMF uygulanmış fidanlarda tespit edilmiştir. Yan kök sayısı da kök uzunluğu karakteri gibi beslenme ve stres koşullarına dayanıklılık açısından kök morfolojisi ile ilgili olarak yakından incelenmesi gereken önemli bir değişkendir. Bu değişken kapsamında özellikle ilk yıllardan itibaren bitki besin maddelerinin alımında önemli bir fonksiyonu bulunan yan köklerin incelenmesi ve yapılan doğal ya da doğal olmayan uygulamaların etkilerinin belirlenmesi önem taşımaktadır. AMF aşılı ve kontrol gruplarından alınan fidan örnekleri üzerinde gerçekleştirilen sayımlarda yan kök sayısının 6,10-14,80 adet arasında değiştiği belirlenmiştir. AMF uygulamasının kök uzunluğu değişkeninde olduğu gibi yan kök sayısı üzerinde de olumlu etkiler meydana getirdiğini istatistiki analizler sonucunda da söylemek mümkündür. Bu konuda yapılan bir başka çalışma sonucunda da tarım bitkilerinde AMF uygulamasının hem toprak koşulları üzerinde hem de kök yapısı üzerinde olumlu etkiler meydana getirerek yaşama sürecini olumlu yönde etkilediği ve bitkilerin büyüme performanslarını önemli ölçüde yükselttiği saptanmıştır. Yine çalışmalarda bu uygulamanın zararsız etkilerinin çokluğuna bağlı olarak ürün veriminde kök ve gövde gelişiminde pozitif artışlara bağlı olarak dönemsel bazda \%23-37 arasında artışların sağlanabildiği belirtilmektedir (Yu vd., 2011). Özbucak ve Kabul (2019) yapmış oldukları çalışmada, mikoriza uygulanmış ve uygulanmamış domates bitkisinde farklı fungusit dozlarının meyve kalite parametreleri üzerindeki etkilerinin karşılaştırmış ve sonucunda mikorizanın fungusit uygulamasına rağmen meyve üzerinde olumlu etkileri olduğunu göstermişlerdir. Yılmaz ve Gül (2009) tarafından yapılan bir çalışmada arbusküler mikorizal fungus aşılamasının patlıcan (Solanum melongena) yetiştiriciliği üzerine etkilerini araştırmış ve sonucunda mikorizanın bitki gelişimi ve ona bağlı olarak da verim artışı sağladığını belirtmişlerdir. Özer (2008) tarafından yapılan bir çalışmada bazı kavun genotiplerinde arbusküler mikorizal fungus uygulamalarının fide gelişimi ve Fusarium oxysporum f.sp. melonis'e dayanıklılık düzeylerine etkilerini araştırmış ve sonucunda genel olarak AMF uygulamalarının fide gelişim parametrelerinde pozitif etki oluşturduğunu belirlemişlerdir. 
Yaşama yüzdesi karakterinin \%99 güven düzeyinde anlamlı olduğu görülmektedir. Yaşama yüzdesi karakterinin ortalama değerleri Tablo 2'de verilmiştir. Varyans analizi sonuçlarına göre türlerin istatistiki olarak aralarında \%95 güven düzeyinde anlamlı farklılıklar bulunan karakterlerden oluşturulan homojen gruplara göre yaşama yüzdesi karakterinde en yüksek değerler AMF uygulanmış fidanlarda tespit edilmiştir. Orman ağacı türlerine ait fidanlar kullanılarak gerçekleştirilen ağaçlandırma ve rehabilitasyon çalışmalarında ilk yıllardan itibaren gerek tür ve orijin bazında gerekse ağaçlandırma yatırımlarının geneli düzeyinde başarının belirlenmesinde göz önünde bulundurulan en önemli kriter adaptasyon yeteneğidir. Adaptasyon yeteneğinin ise tespitinde kullanılan en uygun değișken ise yaşama yüzdesi değişkenidir. Belirli aralık mesafe ile gerçekleştirilen uygulamalarda yaşama yüzdesinin belirlenmesi ya hektar olarak birim alan üzerinden ya da alınan örnekleme alanı üzerinde gerçekleştirilmektedir. $\mathrm{Bu}$ anlamda, AMF uygulamaları sonucunda üç farklı yükselti kademesinde gerçekleştirilen arazi denemelerinde yaşama yüzdesi değişkeni de birinci yıl sonunda belirlenmiștir. Yapılan sayım ve tespitler sonucunda yaşama yüzdesinin tüm denemenin genelinde \%62,54-95,12 arasında değişim gösterdiği tespit edilmiştir. Yapılan istatistiki analizler sonucunda AMF uygulamaları yapılan doğu kayını fidanları ile kontrol fidanları arasında tüm yükselti kademelerinde anlamlı farklılıklar ortaya çıkmıştır. Buna göre AMF uygulanan doğu kayını fidanları her üç yükselti kademesinde de kontrol fidanlarına göre yaklaşık \%30-40 arasında daha yüksek yaşama yüzdesine sahip olmuşlardır. $\mathrm{Bu}$ durum ağaçlandırma, yapay gençleştirme, rehabilitasyon ve restorasyon uygulamalarında araştırma alanında doğu kayını ile yapılacak uygulamaların başarısı üzerinde oldukça yüksek düzeyde olumlu etkiler yapmaktadır. Böylece doğu kayını ile yaygın olarak gerçekleştirilen ormancılık faaliyetlerinin AMF uygulamaları ile başarısını artırarak ve garanti altına alarak dış stres koşullarına dayanıklı primer orman kurma çalışmalarının başarıyla gerçekleştirilme olasılığı yükselmektedir. Bu konuda rotasyon süreleri kısa olmasına karşın başta ağır metal kirliliği olmak üzere sürekli olarak çevre kirliliği sorunlarına maruz kalan tarım bitkilerinin yetiştirilmesinde ve fidanlarının üretilmesinde de çok önemli sonuçlar elde edilmiş ve AMF uygulamalarının tarım bitkilerinde yaşama yüzdesini \%50’lere varan oranlarda artırabildiği tespit edilmiştir (Mondal vd., 2015).

Tablo 2. AMF uygulamasının fidan karakteristikleri üzerindeki ortalama değerlere ait Duncan testi sonuçları.

\begin{tabular}{|c|c|c|c|c|c|c|c|}
\hline Uygulama & 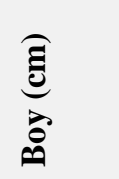 & 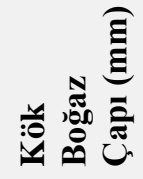 & 矛 芯 & 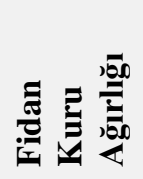 & 范芯 & 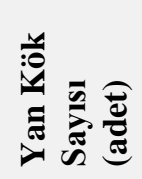 & 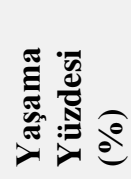 \\
\hline Kontrol & $30,01^{\mathrm{a}}$ & $0,52^{\mathrm{a}}$ & $7,97^{a}$ & $4,45^{a}$ & $22,77^{\mathrm{a}}$ & $6,10^{\mathrm{a}}$ & $62,54^{\mathrm{a}}$ \\
\hline 1. Kademe (200-400) & $31,90^{\mathrm{a}}$ & $0,72^{\mathrm{b}}$ & $8,74^{\mathrm{b}}$ & $5,73^{b}$ & $24,39^{\mathrm{a}}$ & $10,10^{\mathrm{b}}$ & $76,26^{\mathrm{b}}$ \\
\hline 2. Kademe (400-600) & $38,83^{\mathrm{b}}$ & $0,77^{\mathrm{b}}$ & $9,07^{b}$ & $5,17^{\mathrm{b}}$ & $25,95^{\mathrm{a}}$ & $10,80^{\mathrm{b}}$ & $83,61^{\mathrm{c}}$ \\
\hline 3. Kademe (600-800) & $43,56^{c}$ & $0,85^{b}$ & $8,72^{b}$ & $6,52^{\mathrm{c}}$ & $31,39^{b}$ & $14,80^{\mathrm{C}}$ & $95,12^{\mathrm{d}}$ \\
\hline
\end{tabular}

**Aynı harfi gösteren değerler ortalamalar arasında $\mathrm{p}<0,05$ düzeyinde istatistiki anlamda fark olmadığını ifade etmektedir.

\section{Sonuç ve Öneriler}

$\mathrm{Bu}$ araştırmada, doğu kayınları fidanlarında arbusküler mikorizal fungus aşılaması yapılmış, AMF uygulanan ve uygulanmayan tüplü fidanlar Yenice yöresinde 3 farklı yükselti kademesine (200-400 m, 400-600 m. ve 600-800 m.) dikilmiş ve arazi performansları izlenmiştir. Hem yükselti kademelerinin kendi içinde hem de kendi arasında karşılaştırmalar yapılmış ve fidanlıkta kantitatif karakterler (yükselti, boy, kök boğaz çapı, fidan taze ağırlığı, fidan kuru ağırlığı, kök uzunluğu, yan kök sayısı ve yaşama yüzdesi) ölçülmüştür. Ölçümlerin sonucunda AMF aşılı ve kontrol fidanları arasındaki karşılaştırmalar varyans analizi ve Duncan testi yardımıyla yapılmış ve \%95 güven düzeyinde anlamlı olan karakterler kendi arasında oluşturduğu homojen gruplar ile birlikte verilmiştir.

Çalışma sonucunda, AMF uygulamasının boy karakterleri üzerindeki ortalama değerleri ele alındığında en düşük değer 1. yükseklik kademesi 200-400 m.'de AMF uygulanan grupta elde edilmiştir. AMF'li yükseklik kademelerinde en yüksek değer 3. yükseklik kademesinde 600-800 m.'de elde edilmiştir. Boy karakteri \%99,9 güven düzeyinde anlamlıdır. Kök boğaz çapı karakteri bakımından AMF uygulanan yükseklik kademelerinde en yüksek değer 3. yükseklik kademesinde 600-800 m.'de elde edilirken en düşük değer ise 1. yükseklik kademesinde 200-400 m.'de elde edilmiştir. Fidanların taze ağırlığı karakteri bakımından çalışma sonucunda, en yüksek değerin 3. yükseklik kademesinde 600-800 m.'de elde edilirken en düşük değer 1. yükseklik kademesinde 200-400 m.'de elde edilmiştir. Fidanların kuru ağırlı̆̆ karakteri bakımından yapılan analiz sonucunda, AMF uygulanan yükseklik kademeleri arasında karşılaştırma yapıldığında, en yüksek değer 2. yükseklik kademesinde 400-600 m. ve en düşük değer 1. yükseklik kademesinde elde edilmiştir. Kök uzunluğu karakteri bakımından yapılan değerlendirmelerde en düşük değer 1. yükseklik kademesinde 200-400 m.' de elde edilmiştir. En yüksek değer ise 3. yükseklik kademesi olan 600-800 m.'de elde edilmiştir. Yan kök sayısı karakteri bakımından yapılan incelemelerde en yüksek değer 
3. yükseklik kademesindeki AMF’li doğu kayını fidanlarında saptanmıştır. Yaşama yüzdesi AMF uygulanan doğu kayını fidanları kontrol fidanlarına göre yaklaşık \%30'luk bir üstün gösterirken, yükseklik kademeleri içerisinde karşılaştırma yapıldığında en yüksek değer 3. yüksek kademesindeki AMF'li fidanlarda tespit edilmiştir. Araştırma sonuçları genel olarak değerlendirildiğinde doğu kayını fidanlarında büyümeye ilişkin tüm morfolojik karakterlerde ve yaşama yüzdesinde AMF uygulaması, kontrol örneklerine göre olumlu etkiler meydana getirmiş, hem büyümeyi hem de adaptasyon yeteneğini tüm yükselti kademelerinde olumlu yönde etkilemiştir.

Bu konuda yapılan önceki araştırmalara incelendiğinde, ulusal ve uluslararası ölçekte arbusküler mikorizal funguslar ile doğu kayını fidanlarına aşılama uygulaması yapılmış herhangi bir çalışma bulunamamıştır. Bu nedenle yapılan bu çalışmanın sonuçları AMF aşılamasının doğu kayının gelişimi ve tutma başarısı üzerine etkilerinin araştırılması açısından oldukça önemlidir. Bu çalıșma ile AMF aşılamasının doğu kayınının gelișimi üzerinde nasıl bir etkiye sahip olduğu ortaya konulmuştur. Arbusküler mikorizal fungusların bitkilere sağlamış oldukları katkılar göz önüne alındığında, yapılan çalışma sonucunda AMF aşılanmış kayın fidanlarının AMF aşılaması yapılmayan kontrol fidanlarına göre gelişimi ve adaptasyon başarısının artacağı ortadadır. Bu kapsamda diğer kimyasal maddelere yüksek harcamalar yapılarak gerçekleştirilecek yatırımlar yerine türün doğal yaşam ortamı koşullarında topraktan selekte edilecek aktif mikorizaların fidanlara uygulanması, doğu kayınında yeni orman kurma çalışmalarının karşılaşabileceği riskleri ve başarısızlık olasılıklarını en alt seviyeye çekmekte önemli katkıları olacaktır. Bu itibarla ekolojik koşulların ve dengenin dikkate alınarak gerçekleştirilen doğaya uygun ormancılık faaliyetlerinin temelini oluşturan doğal maddelerin, fidan yetiştirme ve kullanım çalışmalarında uygulanması, AMF uygulamaları gibi başarılı sonuçlar ortaya çıkarmakla kalmamakta aynı zamanda söz konusu doğal kaynakları dış etmenlere ve stres faktörlerine karşı daha dayanıklı hale getirerek stabil ve dayanıklı orman kaynaklarının oluşturulmasına hizmet etmektedir. Bu durum çok sayıda ürün ve fonksiyonel hizmetleri sağlayan doğal orman kaynaklarını sağlıklı ve artan kalite koşulları çerçevesinde gelecek nesillere aktarmaya büyük katkılar sağlayacaktır. Dolayısıyla AMF uygulamalarının gençlikte yavaş büyüyen fakat orman ekosistemi için çok önemli olan doğu kayını gibi geniş ve iğne yapraklı orman ağacı türlerinin fidanlarının yetiştirilmesinde kullanılması biyolojik, teknik, ekonomik ve ekolojik açıdan çok büyük faydalar sağlayacaktır.

\section{Kaynaklar}

1. Atay, İ. (1987). Doğal Gençleştirme Yöntemleri. I-II, İ.Ü Fen Bilimleri Enstitüsü, İ.Ü Yayın No: 3461, F.B.E Yayin No: 1, İstanbul, $290 \mathrm{~s}$.

2. Atalay, İ. (1992). Kayın Ormanlarının Ekolojisi ve Tohum Transfer Yönünden Bölgelere Ayrılması. OATIAM Yayin No: 5, Ankara, 209 s.

3. Anon., (2019). Yenice-Çitdere Detay Silvikültür Planı. Yenice, 35s.

4. Citterio, S., Prato, N., Fumagalli, P., Aina, R., Massa, N., Santagostino, A., Sgorbati, S., Berta, G. (2005). The arbuscular mycorrhizal fungus Glomus mosseae induces growth and metal accumulation changes in Cannabis sativa L. Chemosphere, 59(1), 21-29.

5. Demirbaş, A. (2012). Fertigasyon ve mikoriza uygulamalarının domates ve biber bitkilerinin verimine ve besin elementleri alımına etkileri, Doktora Tezi, Çukurova Üniversitesi, Fen Bilimleri Enstitüsü, Toprak Bilimi ve Bitki Besleme Anabilim Dalı, Adana.

6. Hodge, A., Berta, G., Doussan, C., Merchan, F., \& Crespi, M. (2009). Plant root growth, architecture and function. Plant and Soil, 321(1-2), 153-187.https://doi.org/10.1007/s11104-009-9929-9.

7. Janos, D. P., Scott, J., Aristizábal, C., Bowman, D. M. J. S. (2013). Arbuscular-mycorrhizalnetworks inhibit Eucalyptus tetrodonta seedlings in rain forest soil microcosms. PLoSOne, https://doi.org/10.1371/journal.pone.0057716.

8. Koch, A. M., Antunes, P. M., Maherali, H., Hart, M. M., \& Klironomos, J. N. (2017). Evolutionary asymmetry in the arbuscular mycorrhizal symbiosis: conservatism in fungal morphology does not predict host plant growth. New Phytologist, 214(3), 1330-1337.

9. Kothari, S. K., Marschner, H., \& George, E. (1990). Effect of VA mycorrhizal fungi and rhizosphere microorganisms on root and shoot morphology, growth and water relations in maize. New Phytologist, 116(2), 303-311.

10. Kılavuz, A. (2006). Artan Dozlarda Tuz ve Fosfor ile Mikoriza Uygulamasının Nohut (Cicer arietinum 1.) Bitkisinde Verim, Azot, Fosfor ve Potasyum İçeriğine Etkisi. Yüksek Lisans Tezi, YYÜ, FBE, Toprak ABD. Van, 32 s.

11. Mondal, N. K., Das, C., \& Datta, J. K. (2015). Effect of mercury on seedling growth, nodulation and ultrastructural deformation of Vigna radiata (L) Wilczek. Environmental Monitoring and Assessment, 187(5), 241. 
12. OGM (2006). Orman Varlığımız. Orman Genel Müdürlüğü, Ankara, 72 s.

13. Özbucak, T., Kabul, D. (2019). Mikoriza uygulanmış ve uygulanmamış domates bitkisinde farklı fungusit dozlarının meyve kalite parametreleri üzerindeki etkilerinin karşılaştırılması. Journal of Adnan Menderes University, Agricultural Faculty, 16(2): 161-168.

14. Özel, H.B. (2007). Bartın ve Devrek Doğu Kayını (Fagus orientalis Lipsky.) Ormanlarında Meșcere Kuruluşları ve Grup Gençleştirme Uygulamalarının Başarısını Etkileyen Faktörler. ZKÜ Fen Bilimleri Enstitüsü Orman Mühendisliği Anabilim Dalı Doktora Tezi, Bartın, 272 s.

15. Özer, A. (2008). Bazı Kavun Genotiplerinde Arbuscular Mikorizal Fungus Uygulamalarının Fide Gelişimi ve Fusarium oxysporum f.sp. melonis'e Dayanıklılık Düzeylerine Etkileri, Selçuk Üniversitesi, Fen Bilimleri Enstitüsü, Bahçe Bitkileri Anabilim Dalı, Yüksek Lisans Tezi, Konya, 63s.

16. Poss, J. A., Pond, E., Menge, J. A., Jarrell, W. M. (1985). Effect of salinity on mycorrhizal onion and tomato in soil with and without additional phosphate. Plant and Soil, 88(3): 307-319.

17. Saatçioğlu, F. (1976). Silvikültür I, Silvikültürün Biyolojik Esaslarl ve Prensipleri, $236 \mathrm{~s}$.

18. SPSS Inc. (2007). SPSS for Windows, Version 16.0. Chicago: SPSS Inc.

19. Yılmaz, E., Gül, A. (2009). Topraksız ortama arbusküler mikoriza aşılamanın patlıcan (Solanum melongena L.) yetiştiriciliği üzerine etkileri. GOÜ. Ziraat Fakültesi Dergisi, 2009, 26(2), 55-61.

20. Yu, Y., Zhang, S., Huang, H. (2010). Behavior of mercury in a soil-plant system as affectedby inoculation with the arbuscular mycorrhizal fungus glomus mosseae. Mycorrhiza, 20, 407-414. 